Registry (CépiDc/Inserm). Suicide mortality (age-standardised) were calculated in men employees each year from 1976 to 2002 according to economic sector (agriculture sector excluded).

Results Over the period from 1976 to 2002, the age-standardised mortality from suicide is estimated at 25.5/100 000 . There is no significant temporal trend. However, the mortality differs according to economic sector. The human health and social activities present the highest mortality (34.3/100 000) followed by the public administration (29.8/100 000), the construction $(27.3 / 100000)$ and the real estate activities (26.7/100 000).

Conclusions This study points out inequalities of mortality by suicide according to economic sectors. However, there is a relative stability over time in the working population between 1976 and 2002 which is overlapping the trend observed in the general population. Despite some limitations (in particular the absence of agricultural workers and a part of civil servants), these results provide a first assessment on suicide mortality according to economic sectors in France.

\title{
SUICIDE AND OCCUPATION: FIRST ASSESSMENTS FROM FRENCH AVAILABLE DATA
}

Christine Cohidon, ${ }^{1}$ Beatrice Geoffroy-Perez, ${ }^{1}$ Aurélie Fouquet, ${ }^{1}$ Céline Le Naour, ${ }^{1}$ Marcel Goldberg, ${ }^{2}$ Ellen Imbernon'1 $1 / \mathrm{nVS}$, Saint-Maurice, France; ${ }^{2}$ Inserm-U1018, Villejuif, France

10.1136/oemed-2011-100382.141

Objectives Suicide is a complex and multifactorial phenomenon. The number of work-related suicides is difficult to assess in France. There are nevertheless some data available to document this problem. The aim of this study is to describe suicide mortality and its temporal evolution in employees (men) according to economic sectors in France.

Methods The description of suicide mortality comes from the Cosmop programme, conducted by the Department of Occupational Health/InVS. Individual administrative occupational data (DADS-Panel/Insee) have been linked to the medical causes of death from the French National Death 